\title{
Effect of temperature on the sliding wear behavior of laser surface alloyed Ni-base on $\mathrm{Al}-\mathrm{Mg}-\mathrm{Si}$ alloy
}

\author{
Yao-Chih Chuang ${ }^{\mathrm{a}, *}$, Shih-Chin Lee ${ }^{\mathrm{a}}$, Hsin-Chih Lin ${ }^{\mathrm{b}}$ \\ ${ }^{a}$ Department of Materials Science and Engineering, National Cheng Kung University, Tainan, Taiwan \\ ${ }^{\mathrm{b}}$ Department of Materials Science and Engineering, National Taiwan University, Taipei, Taiwan \\ Received 2 December 2005; accepted 9 February 2006 \\ Available online 4 April 2006
}

\begin{abstract}
The surface microstructures of $6061 \mathrm{Al}-\mathrm{Mg}-\mathrm{Si}$ alloy coated with laser surface alloyed (LSA) Ni-Cr-B-Si powder and their sliding wear performance have been investigated. Experimental results show that there are three regions, as grayish region (G.R.), dark region (D.R.) and bright region (B.R.), in the pool. The $\mathrm{Al}_{3} \mathrm{Ni}$ and $\mathrm{Al}_{3} \mathrm{Ni}_{2}$ compounds appear in the G.R. and D.R., respectively. The Al-Ni-Cr amorphous structure can be observed in the B.R. The hardness of the LSA specimens is much higher than the Al-matrix. Compared with the Al-matrix, the LSA specimens have excellent sliding wear performance. They have lower friction coefficient and wear rate. The critical temperature of sliding wear resistance of LSA specimen is higher than that of Al-matrix by about $50{ }^{\circ} \mathrm{C}$. The stress relief during thermal treatment will slightly reduce the hardness and the wear resistance of LSA specimens, especially at testing temperature $>200{ }^{\circ} \mathrm{C}$.
\end{abstract}

(C) 2006 Elsevier B.V. All rights reserved.

Keywords: Laser surface alloying; High temperature sliding wear; Nickel-chromium-boron-silicon powders

\section{Introduction}

Aluminum alloys have been used extensively in many industries because of their excellent properties, such as high thermal conductivity, excellent workability and high specific strength. But some drawbacks, like low hardness, poor tribological properties and crevice corrosion resistance, still need to be improved. In the past decades, a considerable number of studies have been made on how to improve the surface properties of aluminum alloys, involving the electroplating, chemical plating, anodizing and thermal spraying [13]. Recently, laser surface alloying (LSA) has been successfully developed to improve the surface properties of various metals and alloys, such as the surface mechanical/chemical properties of wear [4-7], corrosion [8-9] and cavitation erosion resistance [9-11]. Zhang et al. [12] investigated the wear resistance of $\mathrm{Al}$ alloys with and without reinforcement of $\mathrm{Al}_{2} \mathrm{O}_{3}$ particulates. They found that the $\mathrm{Al}$ alloys with reinforcement of $\mathrm{Al}_{2} \mathrm{O}_{3}$ particles by the LSA technique had a higher critical temperature of seizure than those without

\footnotetext{
* Corresponding author. Tel.: +886 6275 7575x61506; fax: +886 62384946. E-mail address: MAXWELL@cubic.mse.ncku.edu.tw (Y.-C. Chuang).
}

reinforcement. The "critical temperature" was defined as the temperature in which a mild wear changed to a severe wear. Song et al. [13] studied the wear properties of $6061 \mathrm{Al}$ alloy with 3 and $20 \mu \mathrm{m} \mathrm{SiC}$ reinforced particulates. Their investigation found that the reinforcement of $\mathrm{SiC}$ particulates could effectively improve the wear resistance of $6061 \mathrm{Al}$ alloy. Martínez et al. [14] worked on the sliding wear of $\mathrm{Al}-\mathrm{Si}$ alloys and $\mathrm{Al}-\mathrm{Si} / \mathrm{SiC}$ composites at elevated temperatures, and demonstrated that the presence of hard $\mathrm{SiC}$ particulates increased the critical temperature by about $40{ }^{\circ} \mathrm{C}$.

The Ni-Cr-B-Si powder is commercially available and is often used on the surface treatment of metals and alloys because of its low melting temperature and high hardness. This powder has been successfully laser-clad or laser surface alloyed onto steels [15], titanium alloys [16] and aluminum alloys [17]. One may notice that the Ni element in this powder has the same crystal lattice with $\mathrm{Al}$, and hence the intermetallic compounds of $\mathrm{Al}_{3} \mathrm{Ni}, \mathrm{Al}_{3} \mathrm{Ni}_{2}, \mathrm{AlNi}$ and $\mathrm{Ni}_{3} \mathrm{Al}$ are easily formed during the processes of laser cladding or laser surface alloying [18]. However, there is no systematic investigation of the LSA Ni-Cr-B-Si on the Al-Mg-Si alloys and their high temperature wear behavior. More experiments are necessary to be carried out to clarify the LSA characteristics on these aluminum alloys. Therefore, this paper aims to investigate the 
surface microstructures of $6061 \mathrm{Al}-\mathrm{Mg}-\mathrm{Si}$ alloys coated with LSA Ni-Cr-B-Si. Their sliding wear performance is also discussed in this study.

\section{Experimental procedure}

The substrate material was an $\mathrm{Al}-\mathrm{Mg}-\mathrm{Si}$ alloy (ASTM 6061 ) with compositions of $1.0 \% \mathrm{Mg}, 0.6 \% \mathrm{Si}, 0.7 \% \mathrm{Fe}$, $0.27 \% \mathrm{Cu}, 0.15 \% \mathrm{Zn}, 0.15 \% \mathrm{Ti}$ and the balance $\mathrm{Al}$ (in wt.\%). The wear samples $\left(\Phi 35 \times 20 \mathrm{~mm}^{3}\right)$ were machined from the as-extruded billets. Before LSA, the samples were sand blasted to increase the surface roughness and reduce the reflectivity of the laser beam. The chemical compositions of the $\mathrm{Ni}-\mathrm{Cr}-\mathrm{B}-\mathrm{Si}$ powder are shown in Table 1 . The $\mathrm{Ni}-\mathrm{Cr}-\mathrm{B}-\mathrm{Si}$ powders are spherical particles with diameters of 70-200 $\mu \mathrm{m}$. LSA was conducted with a $5 \mathrm{~kW}$ continuous transverse flow $\mathrm{CO}_{2}$ laser. The diameter of laser beam was $2.5 \mathrm{~mm}$ with power density of $7.13 \times 10^{4} \mathrm{~W} / \mathrm{cm}^{2}$, and the laser scanning velocity was $10 \mathrm{~mm} /$ s. The sample surface was protected by argon gas during LSA. The powders were delivered to the pool with a flowing rate of about $2 \mathrm{~g} / \mathrm{min}$ by a powder feeding system. In order to analyze the surface properties, the cross-sections of LSA samples were carefully cut perpendicular to the direction of laser scanning. Some LSA samples were subjected to a T6 treatment, namely, being solution-treated at $530{ }^{\circ} \mathrm{C}$ for $2 \mathrm{~h}$, quenched in cold water, and then aged at $170{ }^{\circ} \mathrm{C}$ for $7 \mathrm{~h}$, to compare their properties with the original LSA samples.

The surface microstructures were observed by using an Olympus BH2-UMA optical microscope (OM), a Hitachi S4200 scanning electron microscope (SEM) and a Hitachi HF2000 field emission transmission electron microscope (TEM). The compositions of surface layers were analyzed by using EDS attached to the SEM and TEM. A combined mechanical grinding and ion-beam thinning techniques was employed to prepare the TEM specimens. The hardness was measured by a Vickers Hardness Tester with a load of $50 \mathrm{~g}$ for $15 \mathrm{~s}$. For each specimen, the average hardness value was calculated from at least five test readings.

The sliding wear behavior was examined by a ring-on-flat wear tester, as illustrated in Fig. 1. The testing temperature was precisely controlled between 25 and $250{ }^{\circ} \mathrm{C}$. The flat was made of LSA sample and the counter-body disc was made of SKD61 with the following composition (wt.\%): $0.39 \% \mathrm{C}$, $1.0 \% \mathrm{Si}, 0.4 \% \mathrm{Mn}, 5.2 \% \mathrm{Cr}, 1.4 \% \mathrm{Mo}, 0.8 \% \mathrm{~V}$ and the balance is $\mathrm{Fe}$, which has a hardness of HV630. Before wear testing, the LSA sample was mechanized off about $0.3 \mathrm{~mm}$ from the surface and then polished to a roughness of $\mathrm{Ra} 0.13 \mu \mathrm{m}$ in center-line-average. The operating parameters of sliding wear test were $19.6 \mathrm{~N}$ loading force, $0.7 \mathrm{~m} / \mathrm{s}$ sliding speed and $1000 \mathrm{~m}$ sliding distance.

Table 1

The chemical compositions of the Ni-Cr-B-Si powder (in wt.\%)

\begin{tabular}{lllllll}
\hline Element & $\mathrm{Ni}$ & $\mathrm{Cr}$ & $\mathrm{B}$ & $\mathrm{Si}$ & $\mathrm{Fe}$ & $\mathrm{C}$ \\
\hline $\mathrm{Ni}-\mathrm{Cr}-\mathrm{B}-\mathrm{Si}$ (wt.\%) & Bal. & 14.64 & 3.21 & 4.32 & 3.65 & 0.73 \\
\hline
\end{tabular}

rotary direction

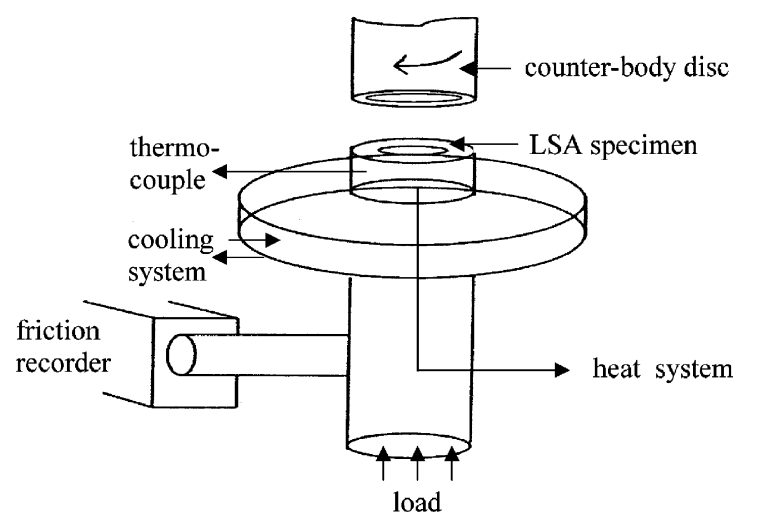

Fig. 1. A schematic representation of ring-on-flat type of wear equipment.

\section{Results and discussion}

\subsection{Microstructure}

Fig. 2 shows the photograph of the cross-section of the pool of LSA specimen. No cracks and porosity are observed in the melted pool. In Fig. 2, three distinct regions indicated as the grayish region (G.R.), dark region (D.R.) and bright region (B.R.) are clearly observed. The SEM observations of G.R. and D.R. are shown in Fig. 3( $a$ and b), respectively. There shows a fine eutectic microstructure in the G.R. (Fig. 3(a)) and a needlelike microstructure in the D.R. (Fig. 3(b)). These fine eutectic and needle-like structures are identified to be $\mathrm{Al}_{3} \mathrm{Ni}$ and $\mathrm{Al}_{3} \mathrm{Ni}_{2}$ compounds, respectively. Fig. 4(a and b) show the TEM micrograph and the diffraction analysis of the B.R. A typical halo pattern in Fig. 4(b) indicates that the B.R. has an amorphous structure. The chemical compositions of this amorphous structure are measured by EDS to be in the range of $44-47 \% \mathrm{Al}, 42-43 \% \mathrm{Ni}$ and $9-13 \% \mathrm{Cr}$ (wt.\%).

Fig. 5 shows the concentration profile of $\mathrm{Al}, \mathrm{Ni}$ and $\mathrm{Cr}$ elements versus the depth from the surface to the bottom along the marked line in Fig. 2. In Fig. 5, one can see that $\mathrm{Ni}$ is dispersed all over the G.R., D.R. and B.R., but $\mathrm{Cr}$ only concentrates in the B.R., namely in the lower region of the

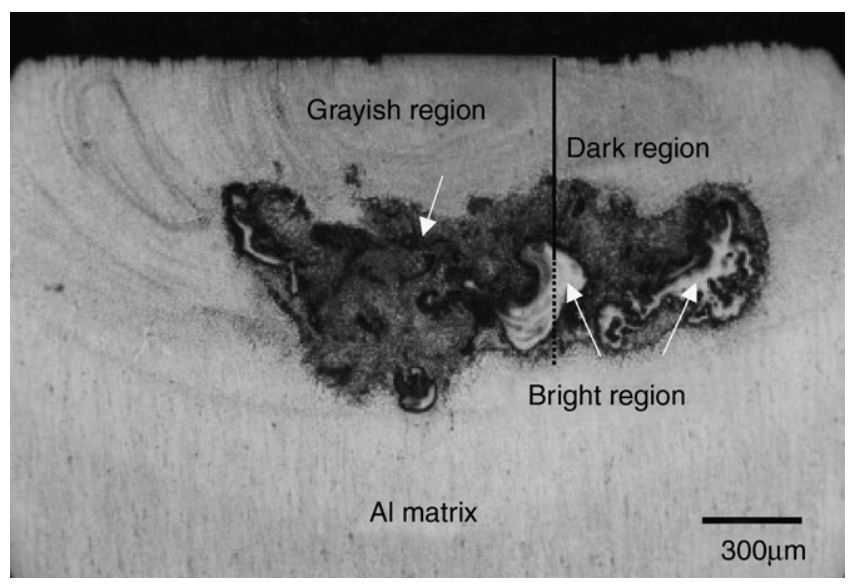

Fig. 2. Photograph of the transverse cross-section of the LSA specimen. 

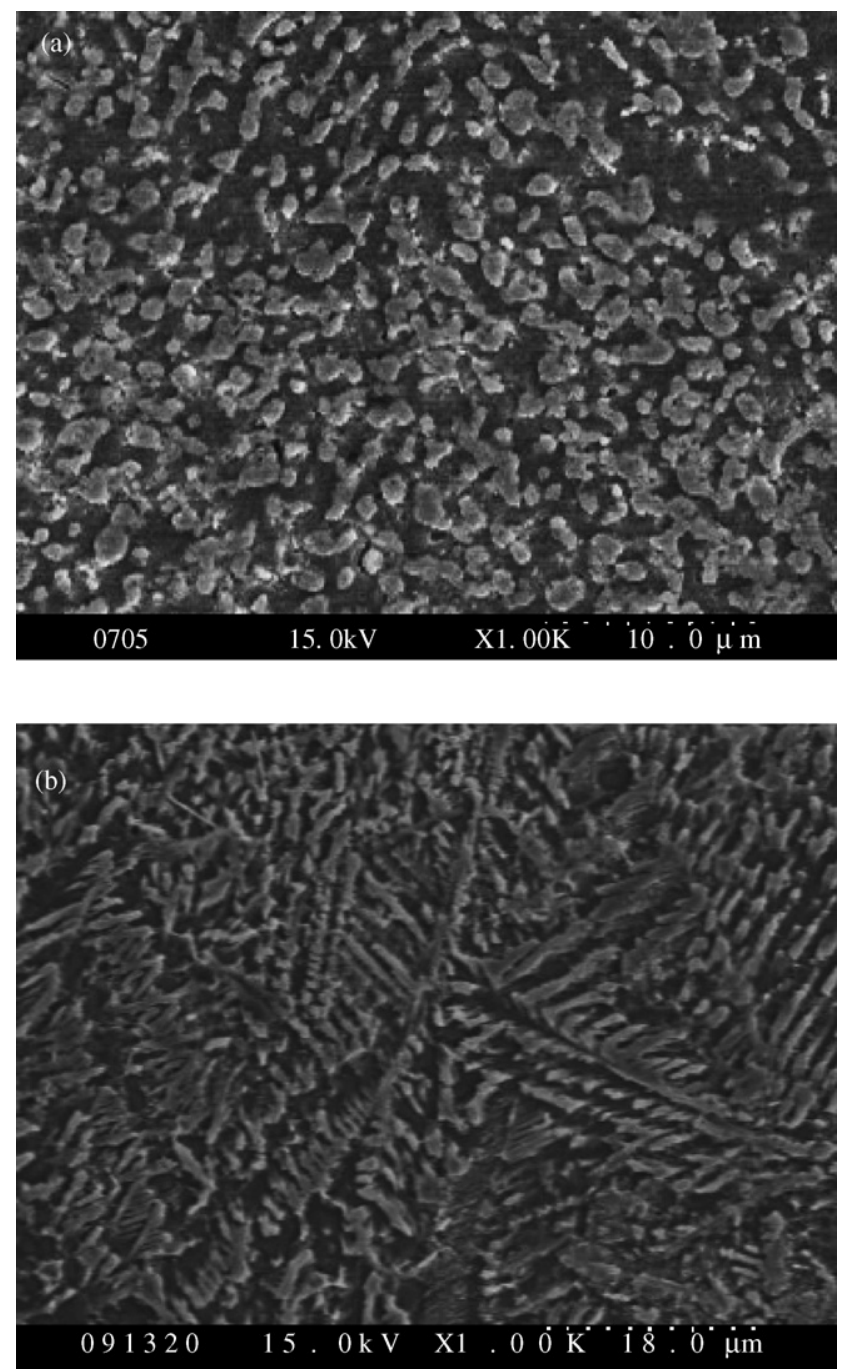

Fig. 3. SEM micrographs of the LSA specimen in the regions of (a) G.R. and (b) D.R.

melted pool. This phenomenon can be ascribed to the lower diffusion coefficient and higher specific gravity of $\mathrm{Cr}$ than other elements. In Fig. 5, one can also find that the content of $\mathrm{Ni}$ increases obviously with increasing depth from the G.R. to D.R. This feature is ascribed to that the Ni element has a higher specific gravity than Al-matrix. The variation of $\mathrm{Ni}$ content is consistent with the formation of $\mathrm{Al}_{3} \mathrm{Ni}$ in the G.R. and $\mathrm{Al}_{3} \mathrm{Ni}_{2}$ in the D.R. In the B.R., Ni content decreases slightly and $\mathrm{Cr}$ content increases as compared with that in other regions. It is well known that $\mathrm{Cr}$ can form solid solution with $\mathrm{Ni}$ in a large composition range [19], because that the atomic radius of $\mathrm{Cr}$ is very similar to $\mathrm{Ni}$. As mentioned above, the $\mathrm{Cr}$ element mainly concentrates in the B.R. It is reasonable to postulate that the $\mathrm{Cr}$ atoms can replace some $\mathrm{Ni}$ atoms in $\mathrm{Al}-\mathrm{Ni}$ compound to form $\mathrm{Al}-\mathrm{Ni}-\mathrm{Cr}$ compound. According to the ternary diagram of $\mathrm{Al}-\mathrm{Ni}-\mathrm{Cr}[20]$, the melting point of the B.R. is higher than $1300{ }^{\circ} \mathrm{C}$. Besides, the average cooling rate is about $10^{4} \mathrm{~K} / \mathrm{s}[17,21]$ in the B.R. Hence, it is reasonable to form an amorphous structure in the B.R., as shown in Fig. 4.
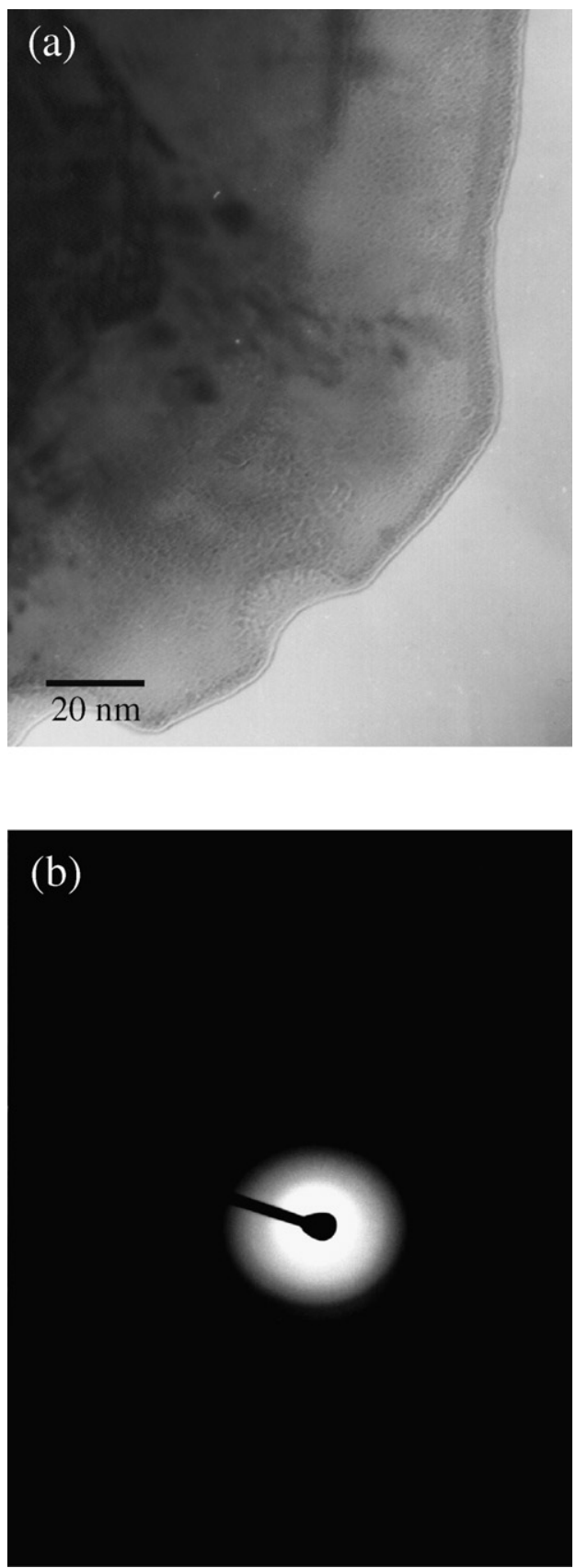

Fig. 4. TEM observation in the B.R. of the LSA specimen. (a) Bright field image; (b) diffraction pattern.

\subsection{Effects of heat treatment}

To understand the effects of heat treatment, the LSA specimens were subjected to a T6 treatment, namely, being solution-treated at $530{ }^{\circ} \mathrm{C}$ for $2 \mathrm{~h}$, quenched in cold water, and then aged at $170{ }^{\circ} \mathrm{C}$ for $7 \mathrm{~h}$. After $\mathrm{T} 6$ treatment, the original $\mathrm{Al}_{3} \mathrm{Ni}$ particles in the G.R. grew up and a lot of tiny $\mathrm{Al}_{3} \mathrm{Ni}$ precipitates formed around the original $\mathrm{Al}_{3} \mathrm{Ni}$ particles, as shown in Fig. 6(a). The similar phenomenon occurred for the needle-like $\mathrm{Al}_{3} \mathrm{Ni}_{2}$ particles. In Fig. $6(\mathrm{~b})$, the original primary dendrites became blunt, and the dendrite arms almost disappeared after T6 treatment. It can also be observed that lots of tiny $\mathrm{Al}_{3} \mathrm{Ni}$ precipitates were introduced within the 


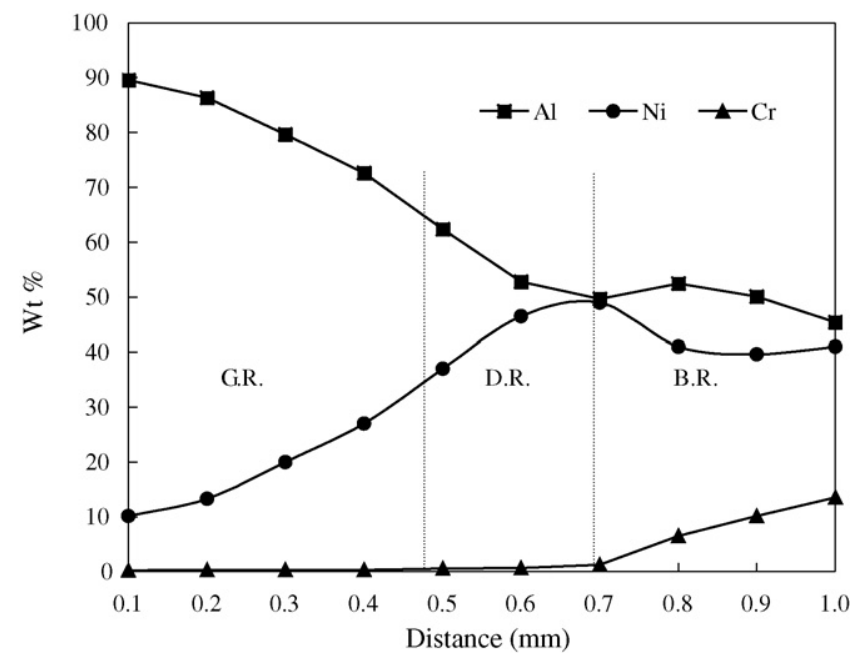

Fig. 5. The distribution of chemical compositions from surface to bottom of the pool.
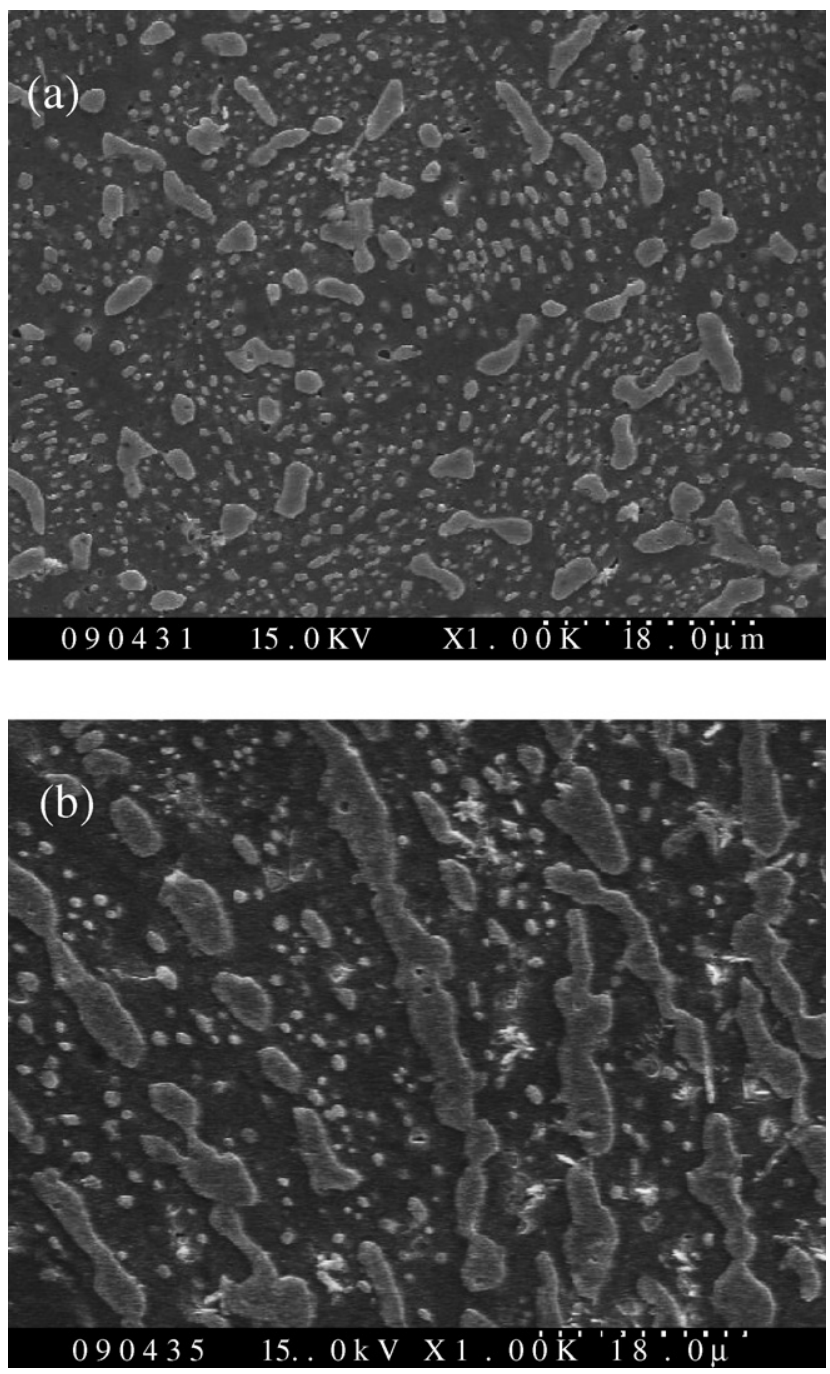

Fig. 6. SEM micrographs of the LSA specimen with T6 treatment. (a) G.R; (b) D.R.
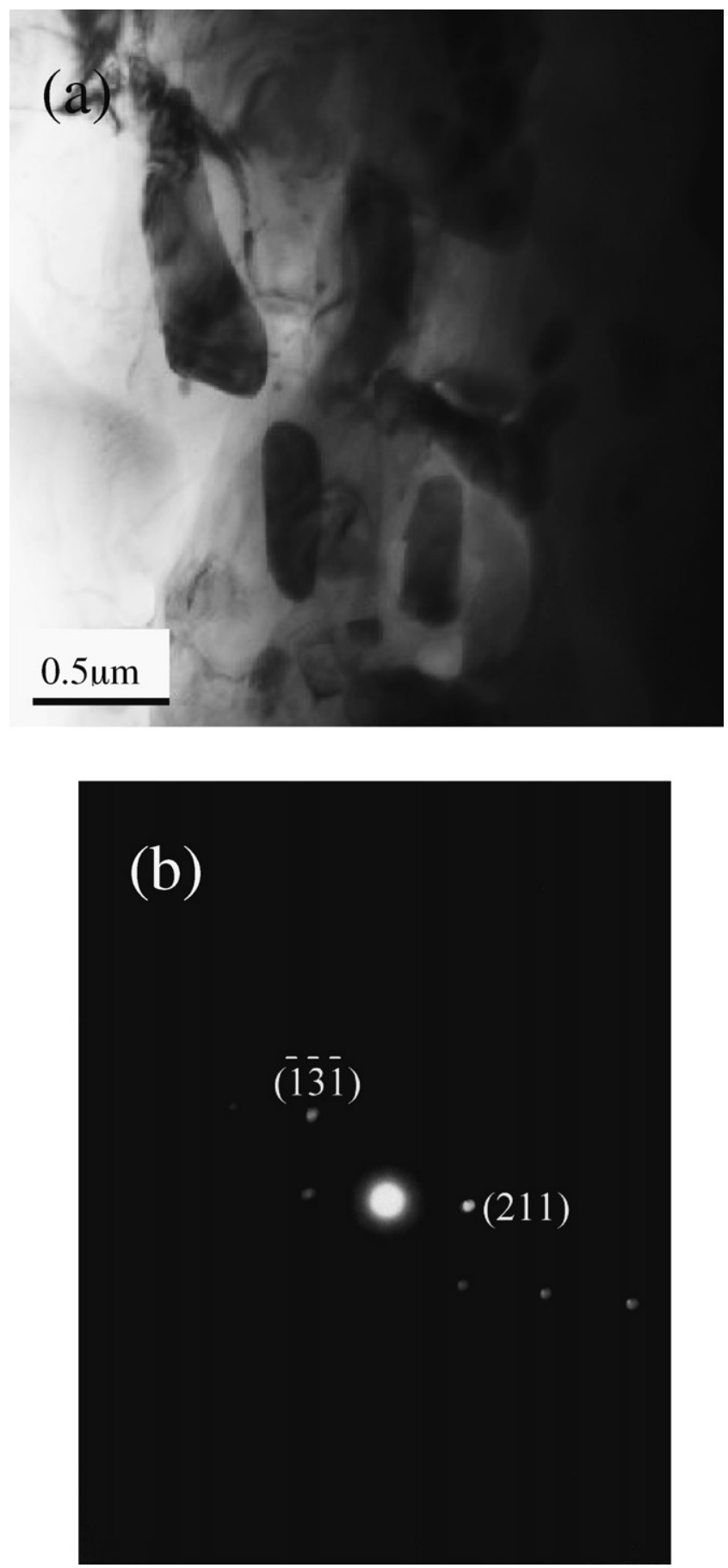

Fig. 7. TEM observation in the B.R. of the LSA specimen with T6 treatment. (a) Bright field image; (b) diffraction pattern.

matrix. Fig. 7(a and b) show the TEM micrograph and diffraction pattern of the B.R. for the LSA specimen with T6 treatment. According to the analysis of diffraction pattern in Fig. 7(b), the precipitates appear in Fig. 7(a) are identified to be $\mathrm{Al}_{3} \mathrm{Ni}$ compounds. Therefore, it can simply conclude that the $\mathrm{Al}_{3} \mathrm{Ni}$ compound can precipitate in G.R., D.R. and B.R. after T6 treatment. This result can be explained as follows. Because of the rapid solidification during the LSA process, there exists a large quantity of supersaturated $\mathrm{Ni}$ atoms. Hence, these excess 


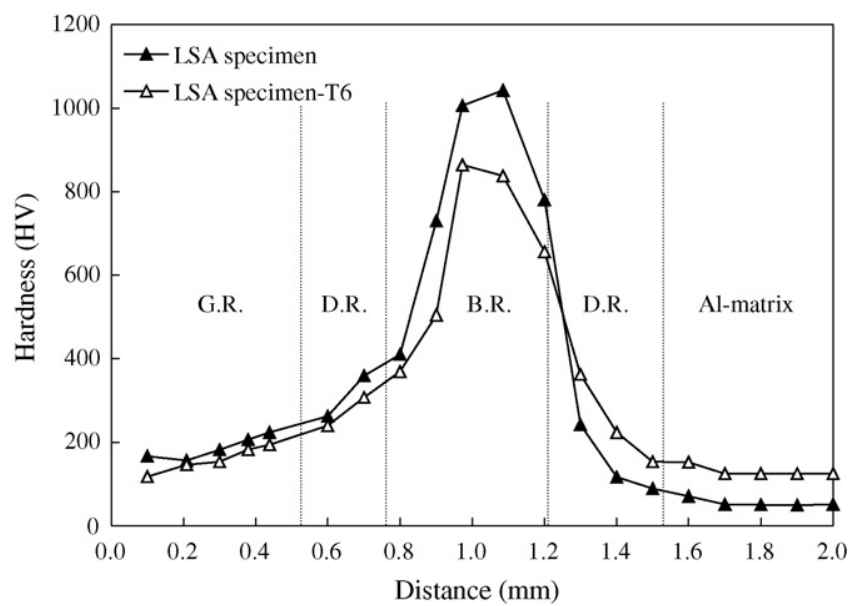

Fig. 8. The profiles of microhardness from the surface to Al-matrix of the LSA specimens.

$\mathrm{Ni}$ atoms will react with the $\mathrm{Al}$ atoms to form the $\mathrm{Al}_{3} \mathrm{Ni}$ precipitates in the following T6 treatment.

\subsection{Microhardness}

Fig. 8 shows the profile of hardness versus depth from the surface to the Al-matrix along the marked line in Fig. 2 for the LSA specimen. It can be well realized that the G.R. and D.R. of the LSA specimen have higher hardness than the Almatrix, due to the existence of $\mathrm{Al}_{3} \mathrm{Ni}$ and $\mathrm{Al}_{3} \mathrm{Ni}_{2}$ compounds. In these regions of LSA specimen, the hardness can reach $\mathrm{HV}$ 125-400, which is approximately two to seven times of the Al-matrix (HV 60). The highest hardness for the LSA specimen is about HV 1100 and occurs in the B.R. The irregular arrangement of atoms of the amorphous structure in this region will introduce large internal stress and increase the hardness. Meanwhile, the large quantity of $\mathrm{Cr}$ atoms in this region will also raise its hardness. In Fig. 8, one can find that the hardness in the B.R. decreases a lot after T6 treatment. This feature is ascribed to the stress relief of the amorphous structure in this region.

\subsection{Wear test}

Wear tests were carried out at $25,100,150,200$ and $250{ }^{\circ} \mathrm{C}$ for both Al-matrix and LSA specimens. Figs. 9 and 10 show the wear rate and friction coefficient versus testing temperature of the wearing test, respectively. As shown in Fig. 9, the LSA specimens have very low wear rate, which is approximately four to eight times less than the Al-matrix at $25-250{ }^{\circ} \mathrm{C}$. The wear rate of these specimens follows a relation: LSA specimen $<$ LSA specimen $\quad$ (T6) $<$ Al-matrix $\quad$ (T6) $<\mathrm{Al}$ matrix. Since the LSA specimens have the $\mathrm{Al}_{3} \mathrm{Ni}$ and $\mathrm{Al}_{3} \mathrm{Ni}_{2}$ reinforced particulates in the G.R. and D.R. and Al-Ni-Cr amorphous structure in the B.R., their hardness can increase to 2-18 times higher than that of Al-matrix, and thereby increase the wear resistance. It can also be observed in Fig. 9 that the slopes of wear rate versus testing temperature exhibit a significant increase between 100 and $150{ }^{\circ} \mathrm{C}$ for Al-matrix and

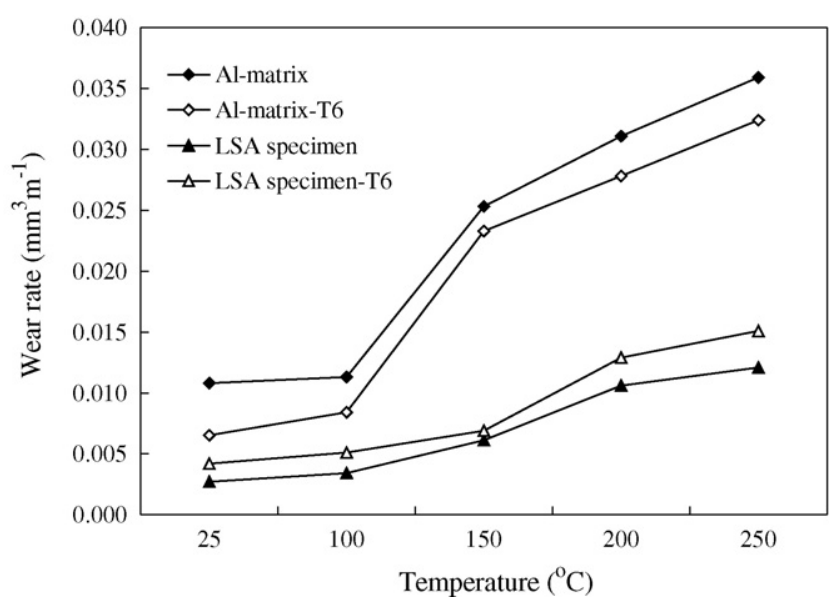

Fig. 9. The curves of wear rate vs. temperature for the specimens of Al-matrix, LSA specimens and T6 treated specimens.

between 150 and $200{ }^{\circ} \mathrm{C}$ for LSA specimens. The similar phenomenon is observed in Fig. 10 for the experimental data of friction coefficient versus testing temperature. These features indicate that the critical temperature of sliding wear resistance of LSA specimen is higher than that of Al-matrix by about $50{ }^{\circ} \mathrm{C}$. This result is consistent with the viewpoint reported by Martinez et al. [14]. Fig. 11(a-c) show the SEM micrographs of the worn surface of LSA specimen which has been subjected to wear sliding at 100,150 and $200{ }^{\circ} \mathrm{C}$, respectively. As can be seen in Fig. 11(a), the worn surface is smooth and the ploughing strips are very shallow. This feature is ascribed to the fact that the $\mathrm{Al}_{3} \mathrm{Ni}$ reinforced particles can improve the wear resistance in the mild sliding wear regime. Upon elevating the temperature to $150{ }^{\circ} \mathrm{C}$, the surrounding $\mathrm{Al}$-matrix begins to soften because its critical temperature of sliding wear resistance occurs between 100 and $150{ }^{\circ} \mathrm{C}$ (as seen in Fig. 9). This feature will reduce the reinforcement of $\mathrm{Al}_{3} \mathrm{Ni}$ particles during the wear sliding. As seen in Fig. 11(b), the reinforced particles are removed from the edge of the strips and the worn surface exhibits a lot of wear debris. When the testing temperature

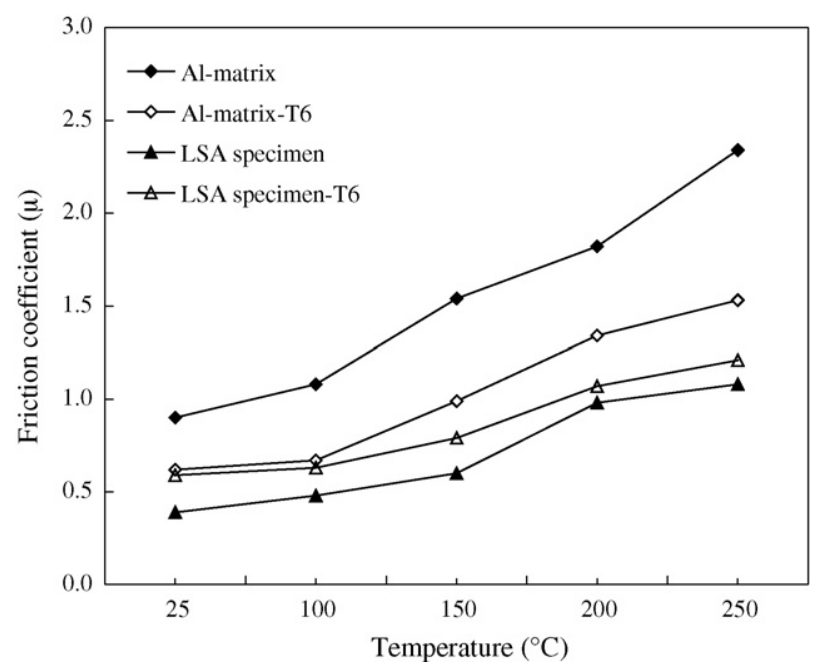

Fig. 10. The curves of friction coefficient vs. temperature for the specimens of Al-matrix, LSA specimens and T6 treated specimens. 

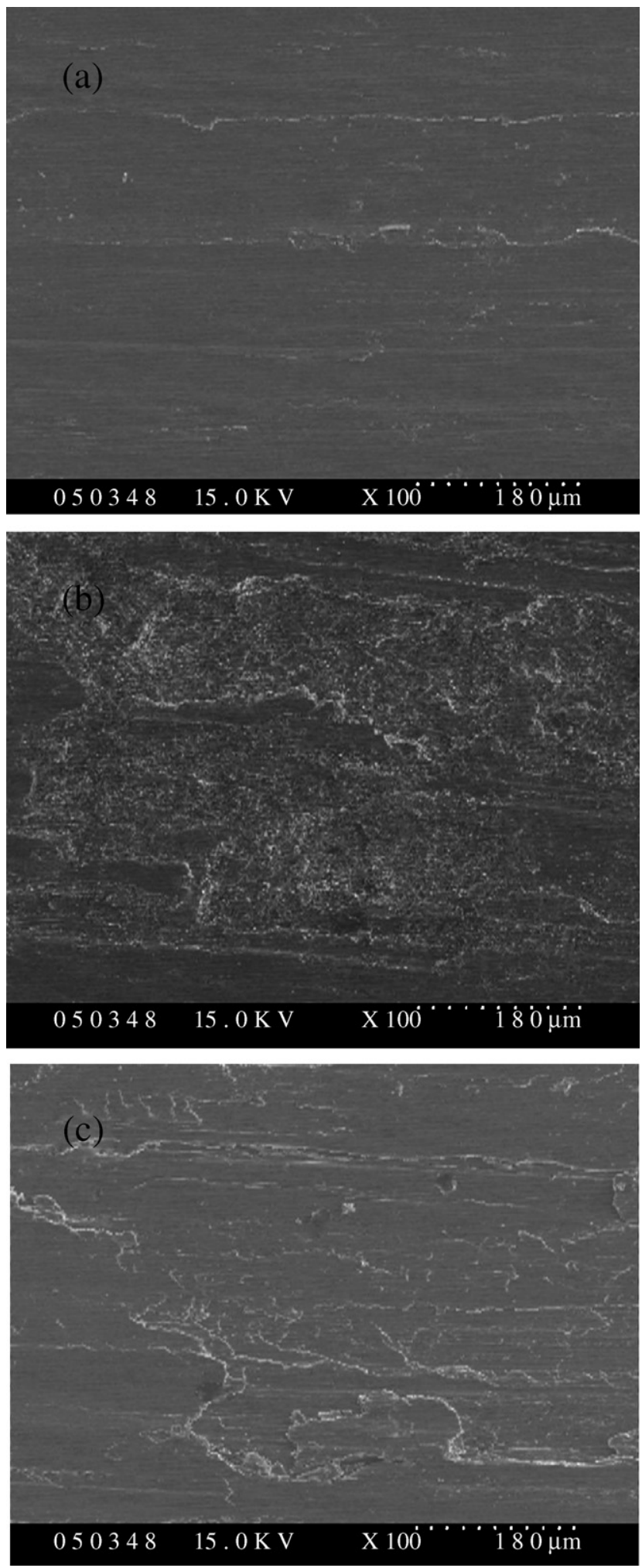

Fig. 11. SEM micrographs of the worn surfaces of LSA specimens with sliding wear at (a) $100{ }^{\circ} \mathrm{C}$; (b) $150{ }^{\circ} \mathrm{C}$; (c) $200{ }^{\circ} \mathrm{C}$.

increases to $200{ }^{\circ} \mathrm{C}$, the failure of $\mathrm{Al}_{3} \mathrm{Ni}$ reinforced particles will result in the removal of the worn surface. However, the larger dimension and higher hardness of $\mathrm{Al}_{3} \mathrm{Ni}_{2}$ particles in the next region and $\mathrm{Al}-\mathrm{Ni}-\mathrm{Cr}$ amorphous structure in the B.R. will provide a more effective wear resistance even the temperature rises up to $200{ }^{\circ} \mathrm{C}$, as shown in Fig. 11(c). This phenomenon can explain why the wear rate does not apparently increase from 200 to $250{ }^{\circ} \mathrm{C}$ in Fig. 9 .

In Fig. 9, one can find that the T6 treatment has a little influence on the wear resistance of Al-matrix and LSA specimen. The wear rate of Al-matrix was slightly decreased by T6 treatment. It is because a large number of $\mathrm{Mg}_{2} \mathrm{Si}$ has been precipitated in the Al-matrix by the peak-aged condition [13]. Therefore, the precipitates increased the hardness of the Almatrix and thereby reduced the wear rate. On the other hand, the wear rate of LSA specimen was increased by T6 treatment, especially at testing temperature $>200{ }^{\circ} \mathrm{C}$. Apparently, the stress relief during the $\mathrm{T} 6$ treatment will slightly reduce the hardness and the wear resistance of LSA specimen.

\section{Conclusions}

The surface microstructures of $6061 \mathrm{Al}-\mathrm{Mg}-\mathrm{Si}$ alloy coated with LSA Ni-Cr-B-Si powder and their sliding wear performance have been investigated. The important conclusions are as follows.

1. There are three distinct regions indicated as the grayish region, dark region and bright region in the melted zone of LSA specimen. The $\mathrm{Al}_{3} \mathrm{Ni}$ and $\mathrm{Al}_{3} \mathrm{Ni}_{2}$ compounds appear in the grayish and dark regions, respectively. The $\mathrm{Al}-\mathrm{Ni}-\mathrm{Cr}$ amorphous structure can be observed in the bright region.

2. The LSA specimens have a much higher hardness than the Al-matrix. The hardness of Al-Ni-Cr amorphous structure in the bright region can even reach HV 1100, which is approximately 18 times of the Al-matrix.

3. The LSA specimens have a very low wear rate, which is approximately four to eight times less than that of the Almatrix at $25-250{ }^{\circ} \mathrm{C}$. Besides, the critical temperature of sliding wear resistance of LSA specimen is higher than that of Al-matrix by about $50{ }^{\circ} \mathrm{C}$.

4. The stress relief in the laser-melted zone during T6 treatment will slightly reduce the hardness and the wear resistance of LSA specimens, especially at testing temperature $>200{ }^{\circ} \mathrm{C}$.

\section{Acknowledgements}

The authors are pleased to acknowledge the financial support of this research by the National Science Council (NSC), Republic of China, under grant no. NSC 89-2216-E-006-078.

\section{Reference}

[1] T. Suzuki, D. Huang, Y. Ikuhara, Surf. Coat. Technol. 107 (1998) 4147.

[2] X.D. Peng, A. Kharlov, V. Bystritski, E. Garate, E.J. Lavernia, Mater. Sci. Eng. A 251 (1998) 142-149.

[3] K. Nakata, M. Ushio, Surf. Coat. Technol. 169-170 (2003) 443-446.

[4] L.J. Yang, Comp. Sci. Technol. 63 (2003) 575-583.

[5] Q. Ming, L.C. Lin, Z.D. Chen, Surf. Coat. Technol. 106 (1998) 174-182.

[6] Y.B. Liu, J.D. Hu, Z.Y. Cao, P.K. Rohatgi, Wear 206 (1997) 83-86.

[7] G.Y. Liang, T.T. Wong, J.M.K. MacAlpine, J.Y. Su, Surf. Coat. Technol. 127 (2000) 233-238. 
[8] T.M. Yue, Y.X. Wu, H.C. Man, Surf. Coat. Technol. 114 (1999) 13-18. [9] H.C. Man, S. Zhang, T.M. Yue, F.T. Cheng, Surf. Coat. Technol. 148 (2001) 136-142.

[10] W.J. Tomlinson, A.S. Bransden, Wear 185 (1995) 59-65.

[11] K.F. Tam, F.T. Cheng, H.C. Man, Surf. Coat. Technol. 149 (2002) 36-44.

[12] J. Zhang, A.T. Alpas, Mater. Sci. Eng. A 161 (1993) 273-284.

[13] W.Q. Song, P. Krauklis, A.P. Mouritz, S. Bandyopadhyay, Wear 185 (1995) 125-130.

[14] M.A. Martínez, A. Martín, J. Llorca, Metall. Mater. 28 (1993) 207-212.

[15] C.T. Kwok, F.T. Cheng, F.T. Cheng, H.C. Man, Surf. Coat. Technol. 107 (1998) 31-40.
[16] R.L. Sun, D.Z. Yang, L.X. Guo, S.L. Dong, Surf. Coat. Technol. 132 (2000) 251-255.

[17] G.Y. Liang, T.T. Wong, Surf. Coat. Technol. 89 (1997) 121-126.

[18] T.B. Massalski (Ed.), Binary Alloy Phase Diagrams, vol. 1, ASM Metal Park, 1986, p. 140.

[19] C.J. Smithells, Metal Reference Book, fifth ed., Butter-worth and Co. Ltd., London, 1976, p. 100.

[20] D.R.F. West, Ternary Equilibrium Diagrams, second ed., Chapman and Hall Ltd., New York, 1982, pp. 96-97.

[21] G.Y. Liang, C.L. Li, J.Y. Su, Mater. Sci. Eng. A 224 (1997) 173176. 